\title{
Sueños de ébano: una mirada a la jurisprudencia y a la vida en los siglos XVIII-XIX ${ }^{1,2}$
}

\author{
Jairo Cieza Mora
}

[...] Tal crueldad es bastante para hacerlos cambiar de naturaleza y aún influir en la organización de su cerebro y de sus facciones. La revolución de la América del Sur y la de la isla de Santo Domingo han suministrado muchas pruebas convincentes de que la capacidad de los negros no es inferior a la de los blancos; pero cuando se les trata como a bestias de carga, ¿qué puede esperarse de ellos?

MilLer, John. Memorias del General Miller al Servicio de la República del Perú, escritas en inglés por Mr. John Miller y traducidas del inglés por el general Torrigas. (Citado por Jean-Pierre TARDieu. El decreto de Huancayo. La abolición de la esclavitud en el Perú.)

1 Dedicado a Napoleón Cieza Burga, director del Archivo Regional de La Libertad, miembro de la Academia Nacional de la Historia, comendador de la Orden del Servicio Civil del Estado, y, sobre todo, mi padre.

2 Nuestro especial agradecimiento a María José Olavarría Parra y Annie Collazos, brillantes alumnas de la Universidad Femenina del Sagrado Corazón y de la Universidad Nacional Mayor de San Marcos, respectivamente. 


\section{Introducción}

Este trabajo fue pensado cuando apreciábamos con curiosidad académica, hace algún tiempo, los excelentes catálogos sobre Real Hacienda (1567-1820) y Corregimiento de Truxillo (tomos I y II) (1537-1784). ${ }^{3}$ Leyéndolos y teniendo a la vista los documentos paleográficos - gracias a la generosidad del director del Archivo Regional de La Libertad y del autor de las paleografías y transcripciones, Walther Arteaga Liñándecidimos redactar, desde nuestra perspectiva (la de un abogado que sabe que el derecho aislado no es nada, pues se trata de una ciencia interdisciplinaria), este artículo histórico-jurídico acerca de la esclavitud en la costa peruana.

La historia nos va a permitir analizar, desde los viejos legajos, la vida y padecimientos de personas que sufrieron una vida oprobiosa y que encontraron en la Real Audiencia, en el Tribunal Eclesiástico o en autoridades regionales competentes una pequeña fisura: que el sistema esclavista les permitía, para lograr una vida más acorde con su condición de personas, utilizar la escritura a través de terceros. Esto que llamamos "fisuras" para alcanzar mejores condiciones de vida, no solo se daban mediante el derecho en su expresión judicial (Real Audiencia o Tribunal Eclesiástico), sino también a través de otras formas no jurídicas, como el cimarronaje, el bandolerismo, la violencia en las panaderías, el trabajo a desgano e incluso el suicidio, los cuales fácilmente nos inducen a imaginar las condiciones que soportaban los esclavos y los libertos. Asimismo, el trabajo y las fuentes consultadas nos permiten deducir que el "camino de la libertad" fue jurídicamente sinuoso, intrincado y complejo, pues no se llegó a resolver con el decreto de agosto de 1821, del Libertador San Martín, sino que recién se concreta en forma definitiva en diciembre de 1854, y más específicamente, en enero de ese año (Ramón Castilla se consolida en el poder sobre Rufino Echenique).

Desde la llegada de los primeros negros que colaboraron con los españoles en la Conquista y su afincamiento en las zonas costeras del Perú, hay trabajos sobre su presencia en Cajamarca, como el de Waldemar Espinoza. Su condición era la de esclavos, con los rigores más extremos que podamos imaginar; no obstante, el derecho abría una rendija

3 Publicados por el Archivo Regional de La Libertad, institución que protege el acervo documentario de la Región La Libertad, en donde transcurren muchos de los casos que aquí presentamos. 
que permitía ir a cuentagotas abriendo el camino para la abolición de tal institución (la esclavitud), que, recordemos, era natural también en el derecho romano y tuvo una expresión jurídica en las Siete Partidas como referente.

En ese sentido, la lucha clasista estaba presente en este complejo camino hacia la libertad. Basta ver los expedientes judiciales de la época para apreciar los intereses contrapuestos entre amos y esclavos, las justificaciones de la oligarquía, ${ }^{4}$ que veían en la liberación de esclavos un retroceso, un exceso temerario de filantropía, un retraso en la producción y en el avance económico del país, y consideraban a esta raza como "personas sin alma", "proclives al vicio y el deshonor"; en buena cuenta, no preparados para la libertad.

Si bien el presente trabajo tiene una connotación histórico-jurídica, no creemos que debamos quedarnos allí, sino que, como todo hecho histórico, debe servirnos para afrontar el presente y el futuro, pues no podemos negar que encontramos las raíces y la herida aún no cerrada de la segregación. El racismo nos limita para formar una nación, y hace caer en letra muerta preceptos constitucionales. La historia es indispensable para el abogado y el profano, pues sin ella no podemos tener la mirada lúcida a fin de no caer en los errores del pasado, ni conoceremos las virtudes que nos permitan encarar con solvencia el futuro.

\section{Contexto normativo de la esclavitud en el Perú}

Existen investigaciones de gran valía en la historia del derecho civil peruano, como el enjundioso y monumental trabajo de Carlos Ramos Núñez y el riguroso estudio de Fernando de Trazegnies Granda.

\subsection{Las Partidas}

Como señala Fernando de Trazegnies en su conocido trabajo Ciriaco de Urtecho. Litigante por amor: 5

4 Tomamos esto, pese a ser un término usual en Aristocracia y plebe del historiador Alberto Flores Galindo.

5 Este libro, histórico-jurídico, narra la historia y peripecias de un hombre libre que quiere recuperar a su esposa esclava y al que se le niega su venta por requerírsele un precio irrazonable. Para conseguir su propósito, utiliza los medios legales a su alcance. 
El cuerpo legal más importante que rige las relaciones de esclavitud ${ }^{6}$ es el constituido por las Partidas de Alfonso el Sabio. Como es conocido [...] no fueron originalmente leyes, sino comentarios jurídicos y de buen gobierno en el más amplio sentido de estos términos. Sin embargo, la frecuencia con que fueron citadas y el peso de la tradición, unidos a su fino razonamiento, les otorgaron jerarquía de fuentes formales del derecho. En el siglo XVIII [...] eran profusamente utilizadas por los litigantes para sostener sus puntos de vista. Las Partidas expresan con palabras muy elocuentes su condena a la esclavitud en forma general; empero, la admiten y la reglamentan [...]. Las Partidas tienden a considerar la esclavitud como un rezago anacrónico de otros tiempos, pero que no ha sido posible erradicar totalmente [...] (Trazegnies 1995: 102, cursivas nuestras).

Como se observa, estos comentarios jurídicos establecían que el esclavo era una cosa; sin embargo, no hay que descontextualizar el supuesto de hecho normativo. En el tiempo de las Partidas, cosa y persona no eran lo que hoy son para nuestro derecho civil. Si, hoy, cosa es un objeto de derecho y persona es un sujeto de derecho o centro de imputación de deberes y derechos, el contexto de las Siete Partidas actuaba, como dice Trazegnies, en degradé. De acuerdo con este contexto, el esclavo, en calidad de cosa, podía acudir a los tribunales a exigir los pocos derechos que tenía, idea que no es compatible con la actual definición (ente inanimado). El esclavo se volvía más "persona" mientras más se acercaba al pater familias. En buena cuenta, era una "cosa personalizada" que utilizaba el arsenal normativo a su alcance para personalizar sus relaciones o vínculos intersubjetivos con su entorno.

Por otra parte, cronológicamente hablando, las Partidas estaban lejos de la presencia esclavista en el Perú de los siglos XVII, XVIII y XIX, pero, claro está, eran un cuerpo normativo regularmente utilizado por los litigantes (esclavos o personas libres que tuvieran vínculos con esclavos). Este conjunto de comentarios, como hemos visto, repudiaba la esclavitud; no obstante ello, la admitían como una institución necesaria para la producción económica. En muchos casos, fueron olvidadas y se decía que no había un valor en ellas, pues no eran normas imperativas. A pesar de ello, esto último no era real: este cuerpo de principios y conceptos

6 Recordemos que en América no se utilizaba el término esclavitud, sino el de servidumbre. 
tenía carácter orientador, como se aprecia de la diversidad de casos en el Perú y otras regiones en donde la esclavitud estaba asentada. ${ }^{7}$

Otro importante punto es el tratamiento del matrimonio en los esclavos, puesto que la Iglesia buscaba que los casados libres con esclavos, o esclavos casados con esclavas, hicieran vida en común, y, de no hacerlo, se estaba faltando un requisito exigido por el dogma de fe. Así, se señala:

Uno de los aspectos legales que interesa más [...] es el que se refiere al matrimonio de personas sujetas a esclavitud [...] la sociedad desalentaba el matrimonio entre esclavos en razón de las limitaciones que la ley establecía para el caso de transferencias de dominio de uno de los cónyuges, lo que normalmente reducía el precio del esclavo. Sin embargo, las Partidas establecen que los siervos pueden casarse entre sí sin necesidad de autorización alguna de sus amos, de manera que el matrimonio era un derecho del esclavo como persona que no le podía ser privado por su amo. Por el contrario, el ejercicio de este derecho por el esclavo llevaba a que, si ambos cónyuges pertenecían a un mismo amo, este no los podía vender separadamente [...] (Trazegnies 1995: 109).

Incluso, "El matrimonio de un esclavo con una persona libre podía eventualmente dar lugar a su manumisión [...]. Las Partidas indican que la libertad se obtiene si el esclavo se casa con persona libre, 'non lo contradiciendo' el señor [...]" (Trazegnies 1995: 111). La manumisión o liberación del esclavo se podía dar por otras causas, pues

7 Trazegnies (1995: 109) nos dice: “Es importante señalar que, de acuerdo a las Partidas, el esclavo no podía ganar nada para sí; todo lo que obtuviera con su trabajo o su ingenio, pertenecía al amo. [...] Sin embargo, con el tiempo, esta regla fue debilitándose [...] algunos esclavos heredaron bienes de sus amos, otros realizaban una actividad agrícola independiente y paralela a la explotación de las tierras del amo o cultivaban estas tierras a cambio de una cantidad sobre las ventas, pudiendo hacer suyo el saldo. En la misma forma, el esclavo pudo hacia el fin del Virreinato dedicarse a un trabajo artesanal o colocarse como jornalero, pagando a su amo una suma fija y quedándose con la mayor ganancia. [...] en algunas ocasiones los esclavos aprovecharon esta libertad de ejercer un oficio para lograr una mejor situación económica; al extremo que en algunos casos utilizaron a su vez trabajadores negros subordinados a ellos. [...]". 
[...] [e]xistían otros casos en los que el señor podía ser forzado a manumitir. Por ejemplo, el señor incurría en causal de pérdida de la esclava "poniendo alguna de sus siervas en la putería públicamente, o en casa alguna, o en otro lugar qualquier, que se diesen a los omes por dinero" [Ley V. Tít. XXII. Cuarta Partida]. Aquí no se trataba ya de "bondades" del esclavo, sino de sanción a lo que era considerado como una falta del amo: la manumisión no era una gracia al siervo, sino un castigo al señor. [...]. ${ }^{8}$

\subsection{Las normas sobre la esclavitud en el Perú. La participación de Inglaterra en la abolición de la esclavitud}

La evolución normativa acerca de la esclavitud en el Perú ha sido de corsi e recorsi, de avances y retrocesos, de intereses y de aparente y real filantropía; normas influidas por el espíritu liberal de la época, que "chocaban" estruendosamente contra una realidad esclavista y feudal en el Perú, cuyos hacendados necesitaban mano de obra para el trabajo en las haciendas y para mantener el modo de producción vigente en la época. Las ideas liberales tocaban una fibra sensible al propugnar la abolición de la esclavitud, pues iban contra un sistema implantado desde el siglo XVI en el país, y el anuncio de la abolición significaba un golpe duro a la oligarquía de la época y al aparato productivo nacional, como manifestaban los comentaristas de la época. Quien quería tener presencia social debía tener al menos un esclavo. ${ }^{9}$

Saponara nos dice al respecto:

La presencia de negros, no solo en la conquista del Perú, sino en toda América, constituyó una violación a la Real Cédula del 6 de setiembre de 1521, dictada en Burgos, que disponía que no se llevasen negros esclavos en las expediciones de descubrimiento, dada su inclinación a fugarse y juntarse con los naturales, sobre los cuales ejercían una influencia perniciosa. Pero la práctica y el tácito consentimiento

8 Trazegnies (1995: 114). Recordemos que estamos citando textualmente, ya que el castellano antiguo era diferente al actual. Para este trabajo, en algunos casos, como el de José Faustino Sánchez Carrión, hemos tenido la valiosa ayuda del paleógrafo del Archivo Regional de La Libertad.

9 Por ello decíamos que la normativa, que planteaba la mejora de la realidad social, no pudo, pese a las ideas liberales que la influían, terminar de manera radical con la esclavitud. 
de los monarcas tornaron inútil esta disposición (Saponara 2008: XXI). ${ }^{10}$

Si bien en algunos casos los negros esclavos llevaban una buena relación con sus amos caritativos (los había), esto no sucedía en las haciendas, en donde no mantenían un trato personal con los amos, pero contaban con mayor espacio para sentirse lejos de su mirada escrutadora. $\mathrm{Al}$ respecto, se dice que la relación con estos negros privilegiados era mejor que con los indios, a quienes se les tenía mayor desconfianza. Sin embargo, los castigos y los abusos con los negros esclavos llegan a ser indescriptibles y horrendos.

Así, "[Los castigos] fueron realmente crueles e inhumanos. Los negros no podían aparearse con los indios; si el negro era varón, se le castraba; y si era hembra, se le cortaba las orejas, esto a manera de ejemplo [...] se les marcarse en la espalda con un hierro incandescente, ${ }^{11}$ la llamada 'carimba'" (Saponara 2008: XXIV).

En la guerra por la independencia "Se formaron así desde antes los regimientos de pardos y morenos que, además de destacarse por su agresividad y valentía en las guerras, lo hacían también por pendencieros y escandalosos en la paz" (Saponara 2008: 5). El gobierno de San Martín, si bien acogía ideas liberales, tenía un objetivo militar y político: la derrota de los realistas y la liberación de América, por lo que es probable que la liberación de esclavos por el gobierno obedeciera a motivos militares, y su devolución - como enseña Saponara - , a consideraciones políticas y sociales. Por este motivo, “Tal vez sea esta una de las razones por la que muchos esclavos prefirieron mantenerse al lado de sus dueños, despreciando la oferta de libertad; libertad que no les garantizaba sino miserias e inseguridad; libertad que tenía un precio y demandaba un posible sacrificio: la vida misma" (Saponara 2008: 9).

10 Manuel Saponara agrega: “Existen documentos notariales que demuestran que indios del común poseían esclavos negros, a pesar de las ordenanzas en contrario emitidas por el licenciado Lope García de Castro en 1565 y el virrey Toledo en 1579, y también presentes en las Complementarias de 1580. [...] Para 1614 los esclavos constituían el cuarenta por ciento de la población limeña, que alcanzaba los 25000 habitantes" (2008: XXII).

11 Esta práctica subsistió hasta fines del siglo XVIII, cuando el 5 de noviembre de 1784 se expidió una real cédula prohibiéndola. 
El esclavo veía que el precio que había que pagar por la libertad era muy alto: la vida misma; sin embargo, muchos fueron los que por propia voluntad se incorporaron al Ejército Libertador y tuvieron una participación importante en la lucha por la independencia. La cercanía de estos con los hacendados generó un distanciamiento entre negros e indios, lo que seguramente no permitió su unión en el momento de luchar por sus anhelos de libertad y vida digna. Quizá este sea el origen de tan conocido recelo en la historia peruana.

\subsection{El decreto de "libertad de vientres" dado por José de San Martín}

Este decreto se otorgó el 12 de agosto de 1821, por San Martín, y señalaba que a partir del 28 de julio de 1821 los hijos nacidos de esclavos no tendrían esta condición. Sin embargo, como afirma Tardieu, "ya se estaba preparando a acudir a otra trata: la de los culíes chinos, para disponer de una ductilidad comparable" (Tardieu 2004: 32).

Asimismo, el 16 de octubre de 1821 se dictó un decreto que prohibía los castigos crueles, salvo cuando el esclavo los mereciera. Cabe preguntarse: ¿quién decidía si el esclavo era merecedor de dichos castigos? Obviamente, el amo.

El gobierno de San Martín - mejor dicho, el Protectorado- dictó el decreto del 17 de noviembre de 1821 y ordenó alistar en el ejército a los esclavos de edades comprendidas entre los 15 y 50 años, lo que guarda concordancia con lo indicado antes. ${ }^{12}$ Siete días más tarde, se dio el

12 Sobre el particular, es interesante citar al virrey Joaquín Pezuela, quien encendidamente señalaba: “ ¿Habéis reflexionado cuál puede y debe ser el fin de la carrera de horrores que habéis principiado? ¿Con qué recursos contáis para emprender una revolución que envuelve en sí la destrucción de vosotros mismos? Hombres incautos, el enemigo de la felicidad del Perú os ha seducido para que sacrifiquéis vuestras vidas a favor de sus planes ambiciosos, y ninguna utilidad, os ha engañado con la halagüeña voz de la libertad, que ni quiere, ni puede daros. Vosotros pertenecéis a la grande nación española, y en ella reside el derecho y el poder de haceros libres y felices. Venid, pues, hijos descarriados: el virrey os llama a nombre de la nación, y bajo su garantía os ofrece la libertad por esta única vez, y sin que sirva de ejemplar para los que se hallan en circunstancias semejantes. Los que seáis útiles para las armas serviréis cinco años solamente: seréis vestidos, alimentados, pagados y considerados en todo en la misma forma que las tropas veteranas del ejército nacional. Concluido el tiempo señalado, seréis dueños de continuar en el servicio o marcharos donde os acomode. No des- 
reglamento correspondiente al decreto del 12 de agosto de 1821, que declaraba la libertad de vientres. Ese mismo día se expidió otro decreto, por el cual en adelante todos los esclavos que llegasen al Perú serían libres de inmediato por el solo hecho de pisar suelo peruano. En él se ordenaba, además, que las autoridades de puertos y fronteras instruyesen a dichos esclavos de la existencia de la ley, para que no dejaran de recibir sus beneficios.

Saponara se pregunta:

¿Significaba esto que los propietarios habían perdido el control sobre sus siervos o que el principio de autoridad, en estas relaciones, estaba ya resquebrajado? Es probable que los amos hubiesen seguido perdiendo el control sobre sus esclavos y que estos se mostraran rebeldes y frustrados por la promesa incumplida del gobierno de manumitirlos a cambio de la prestación de servicios militares, medida que no pudo implementarse como consecuencia directa de la presión que sus dueños, influyentes, ejercían sobre el Estado. [...]. Es probable que el mercado de esclavos desapareciese como consecuencia de su escaso número, lo que debió haber generado un alza en sus precios (2008: 31).

\subsection{La Constitución liberal de $\mathbf{1 8 2 3}$}

La Constitución liberal del 12 de noviembre de 1823 fue clara en su propuesta antiesclavista: "Nadie nace esclavo en el Perú; ni de nuevo puede entrar en él, alguno de esta condición. Queda abolido el comercio de negros".

Asimismo, establecía: "El peruano que fuere convencido de este tráfico, pierde los derechos de naturaleza"; y también: "El extranjero que se ocupare de él, no puede naturalizarse en el Perú".

Si bien la ideología liberal había calado en nuestros juristas de la época, la realidad no correspondía a lo expresado con "la libertad de vientres" de San Martín, ni con esta carta constitucional, pues se dieron reglamentos que contravenían la Constitución y hacían posible, en la práctica, la continuación de la esclavitud.

preciéis este llamamiento que os libra de los males que os amenazan. Presentaos a los comandantes de las partidas y pueblos más inmediatos. Todos os recibirán bien, y os pagarán inmediatamente con el haber del soldado, pues así lo tiene prevenido vuestro virrey". Citado por Tardieu (2004: 26). 
El 24 de marzo de 1824 se dictaría una norma importante, pero no tan agradable para los esclavistas: un decreto suscrito por Bolívar en Trujillo, que permitía a los esclavos cambiar de amo según su conveniencia, siempre y cuando hubiera presupuestos razonables, como el del esclavo que acusaba a su amo de sevicia y pedía ser vendido.

Como se ha mencionado, se dan una serie de decretos que fueron, muchas veces, un saludo a la bandera, tinta en el papel, sin consonancia con la realidad; en merecidas cuentas, entelequia propia de un sistema que se negaba a cambiar con normas impracticables. En este contexto, “[...] el 14 de octubre de 1825 se expidió el decreto sobre Reglamento de Fundos Rústicos o Reglamento de Trabajo; [...] Unanue señalaba [...] ‘La más útil, sabia y vigorosa ordenanza cuanto más alcanza, en el Perú, $a$ que se la coma la polilla'. [...] César Gutiérrez nos dice que la mayoría de los hacendados lo acataron pero que pocos se ciñeron a él; una remembranza del españolísimo 'cumplo pero no acato' de los días de la Conquista” (Saponara 2008: 40).

\subsection{La Constitución de $1834^{13}$}

Terminado el gobierno del mariscal Gamarra, resulta elegido presidente el mariscal José Luis de Orbegoso y Moncada. El 10 de junio de 1834 se promulga la Constitución, la que en el artículo 146 prescribe: "Nadie nace esclavo en el Perú ni entra ninguno que no quede libre".

En las pugnas militares, Salaverry da el decreto del 10 de marzo de 1835, por el cual se permite la importación de esclavos. Era un decreto abiertamente inconstitucional, pero lo justificaban por necesidades de la agricultura y bajo el inefable argumento de que, desde el origen, los negros venían siendo esclavos. Salaverry lo justificó también en la "fuerza invencible de la costumbre", ;como si pudiese existir costumbre contra lege! Además, se decía que lo señalado en la Constitución era "un exceso de filantropía".

Posteriormente, en 1837, el mariscal Santa Cruz firmó un tratado comercial con Gran Bretaña, en donde se hablaba de combatir en conjunto el comercio internacional de negros.

13 Pareja Paz Soldan (2005: 19). Esta Constitución fue aprobada por el Congreso Constituyente y promulgada por el mariscal Orbegoso. Rigió desde el 10 de junio de 1834. Por ley del 22 de agosto de 1939, fue declarada "insubsistente". 


\subsection{La Asamblea Constituyente de Huancayo en 1839}

La Constitución de 1839, aprobada por el Congreso Constituyente de Huancayo y vigente desde el 10 de noviembre de 1839 hasta el 27 de julio de 1855, estableció que nadie nacía esclavo en el Perú. Sin embargo, como manifiesta Saponara, hubo un desfase entre la norma y la realidad: "[...] parecieran contradictorios el espíritu y la letra de la Carta; pero, en realidad, lo que pasó es que a los legisladores de 1839 les faltó valor para manifestar claramente sus intenciones en un documento incontestable como la Constitución" (2008: 53).

Lo increíble de esta ley de leyes es que ni siquiera formalmente guarda congruencia con la Carta de 1834, al omitir que los esclavos que entran en el territorio nacional dejan de serlo, de manera que daba valor al ya mencionado decreto de Salaverry. En forma paralela, la Constitución estipulaba que los libertos, es decir, los nacidos bajo el decreto de San Martín, del 12 de agosto de 1821, debían permanecer sujetos a la tutela de sus amos hasta cumplir los 50 años de edad. Se había cedido ante los argumentos de los juristas Domingo Orué y José María de Pando.

Poco después se daría el decreto del 24 de diciembre de 1839, norma que quiso, "inclusive, coartar la autonomía del Poder Judicial al ordenar a los jueces que se abstuviesen de admitir demandas de negros reclamando su libertad, a menos que la causa fuese por sevicia o decadencia moral del amo, cosas muy difíciles de probar para un esclavo" (Saponara 2008: 54).

\subsection{El golpe final a la esclavitud}

En verdad, la abolición de la esclavitud llega el 3 de diciembre de 1854, durante el gobierno del mariscal Castilla; fue en Huancayo que Castilla la declaró con un decreto ${ }^{14}$ que decía:

El Libertador Ramón Castilla, Presidente Provisorio de la República, decreta:

Los varones y las mujeres tenidos hasta ahora, en el Perú, por esclavos o por siervos libertos, sea que su condición provenga de haber sido enajenado como tales o de haber nacido de vientres esclavos, sea

14 El redactor de esta histórica ley fue Manuel Toribio Ureta. 
que de cualquier modo se hallen sujetos a servidumbre perpetua o temporal: todos, sin distinción de edad, son desde hoy y para siempre eternamente libres.

Dado en casa del Supremo Gobierno en Huancayo a 3 de diciembre de 1854.

\section{Ramón Castilla}

Como sostiene Rodríguez Pastor, “En realidad este decreto no habría trascendido si es que Ramón Castilla no derrotaba al ejército de Echenique, en La Palma (Lima), el 5 de enero de 1855. Solo con el poder político que, a partir de esa ocasión, tuvo Castilla y la gente que lo acompañaba es que recién se pudo llevar adelante el proceso de libertad de los esclavos" (2008: 45).

Con respecto a la reacción de los hacendados dueños de esclavos, Rodríguez Pastor indica: "Los poderosos hacendados en ningún momento dijeron que la abolición de la esclavitud era incorrecta, pero demandaron e hicieron una campaña por una pronta indemnización". ${ }^{15}$ En cuanto a la indemnización, concordamos con Rodríguez en que “Con Castilla no hubo en realidad liberación de esclavos sino una compra masiva de afrodescendientes por parte del Estado peruano, que en esos momentos gozaba de una bonanza económica como consecuencia de los ingresos del guano" (2008: 53).

15 Rodríguez Pastor (2008: 52). Este autor agrega: “En la reunión [los hacendados o sus representantes] hicieron un balance de la situación del agro y tomaron esta posición: ‘la medida de la liberación era justa y reclamada por la civilización del siglo; pero tal como había sido dictada y el carácter coercitivo para llevarla a su cumplimiento, convertía a la ley en una medida inicua. Lo central debió haber sido - añadían - la facilitación de los medios para traer «brazos» al país. [...] se había soltado a 'una clase de hombres no preparados para la libertad'" (2008: 53, cursivas nuestras). "Al menos - agregan - era preciso poner los medios más positivos para que la ruina no fuese irreparable. [...] Con el decreto de Huancayo, '[...] todo esto ha sido echado por los suelos [...]'. Una opinión y conclusión muy de ellos era que 'puede existir un país y prosperar con esclavos, por injusta que sea la institución, pero no puede haber sociedad próspera sin propietarios'" (2008: 53, cursivas nuestras). 


\section{Los juristas de la época y el Código Civil de 1852: los aletazos de el Murciélago y otros jurisconsultos}

\subsection{Manuel Lorenzo de Vidaurre}

Ramos Núñez, a lo largo de su obra, se refiere a Vidaurre y a Manuel Atanasio Fuentes (el Murciélago). ${ }^{16}$ El primero condena la esclavitud, pero no puede orientar a su prescindencia, pues su estatus aristocrático no se lo permite; el segundo la defiende, con esa pluma lacerante y elegante que puede defender las más ignominiosas causas. Como afirma Ramos, de Vidaurre:

Vidaurre se pliega formalmente al derecho romano en cuanto considera que la servidumbre o esclavitud es contraria a la condición natural del hombre, siendo una institución no de derecho natural sino de derecho de gentes y de derecho civil. [...]. Vidaurre elude pronunciarse abiertamente contra tal figura y no se atreve a calificarla de "injusta". Los prejuicios aristócratas del codificador habrían de alertarlo sobre la inminencia de una rebelión negra, generada ante los malos tratos padecidos por los esclavos. Su experiencia de oidor en Puerto Príncipe lo lleva a imaginar una rebelión generalizada de esclavos en la costa peruana. Aterroriza al jurisconsulto un eventual triunfo de la revuelta: "nuestras esposas, nuestras hermanas, nuestras hijas sacrificadas en el tálamo oscuro e infame" (Ramos Núñez 2001: 253).

Con respecto al Código Civil de 1852, el mismo autor expresa:

[...] una de las inclusiones legislativas que mejor graficó el panorama social de la época es la concerniente a los ingenuos, siervos o libertos, prevista en el título 8 de la sección 2. . La Redacción asertiva del artículo 118 del proyecto - “Con relación al estado civil son también las personas ingenuos, siervos y libertos", sin más - fue matizada en el numeral equivalente del artículo 95 del texto definitivo del Código Civil, en que se antepuso un elemento suspensivo: "mientras subsisten los efectos de la antigua esclavitud". El artículo 119 del Proyecto definía como ingenuo - es decir, persona libre - al que "nace de madre libre; el hijo de la madre liberta; y el hijo de aquella que hubiese naci-

16 Ambos juristas de la época son proponentes del Código Civil de 1852. 
do después de jurada la independencia" (Ramos Núñez 2001b: 255256, cursivas nuestras).

\subsection{Manuel Atanasio Fuentes, el Murciélago}

El profesor Ramos escribe: "La clasificación de castas y tipos raciales en la Lima del Ochocientos ocupa un lugar central en la producción de Manuel Atanasio Fuentes. En efecto, numerosos artículos y cuadros de costumbres preparados por el Murciélago revelan las características que se atribuían a los diferentes grupos raciales en la segunda mitad del siglo XIX, desde el punto de vista de un exponente del segmento ilustrado de la sociedad" (2002: 87).

Uno de los libros más difundidos, Lima. Apuntes históricos, descriptivos $y$ de costumbres, era un intento de defender el prestigio de la ciudad y el carácter de sus habitantes ante la mirada de los extranjeros. En la introducción del libro, Fuentes ridiculiza los estereotipos culturales que se construyen a partir de prejuicios etnocentristas. A través de los ejemplos pretende demostrar la inexactitud de los juicios foráneos hacia Lima y sus habitantes (Ramos Núñez 2002: 87).

Un aspecto interesante de el Murciélago se da cuando:

Se advierte en Fuentes un curioso dilema. A la vez que fustiga las prácticas sociales de los grupos subalternos y asume una representación devaluada de los mismos, por otro lado encomia las diferencias raciales. En el fondo, no existían contradicciones. Los prejuicios se manifiestan mejor ante la presencia física del marginado. En una sociedad racialmente homogénea otras serían las pautas de discriminación. Por esta razón, la diversidad racial en Lima para Fuentes sería beneficiosa. La población de la capital, dice, "tiene por fuerza que ser agradable desde que toda ella no se compone de blancos y no es por lo mismo ni igual, ni monótona, ni cansadora de los sentidos" (Ramos Núñez 2002: 90).

Ramos advierte otro aspecto curioso de nuestro personaje:

Aun cuando Manuel Atanasio Fuentes acusaba inocultables raíces africanas en sus rasgos físicos - nariz achatada, cabello ensortijado, ojos enarcados y labios gruesos-, no deja de llamar la atención el tratamiento inusualmente negativo que dispensa a la raza negra, a la 
que asocia a la ignorancia, la falta de modales y los actos delictivos. Fuentes no hizo ningún esfuerzo para comprender que aquellas limitaciones eran culturales, efectos y no causas. Cuando Fuentes describe a los negros y los compara con los indios y los chinos, se sitúa como el consejero de las clases altas para decidir cuál es el peor sirviente y cuál es el más recomendable. Las opiniones que vierte están teñidas, pues, de un conservadurismo nostálgico y un escepticismo ante los cambios que tenían lugar en la política legislativa (2002: 91).

Finalmente, “En un deplorable discurso, el Murciélago diría: 'La pobre zamba tiene más hijos que pelos, y tonta y bobalicona, al fin zamba peruana, no quiere sino que todos sus pimpollos sean con el tiempo gente grande, y no grandes por sus años y por sus méritos, sino por sus oropeles y fatuidad. Resulta pues de esto que ninguno se conforma con ser el último entre todos, o igual a ellos, sino que apetece la superioridad y quiere ejercerla, a toda fuerza'"' (Ramos Núñez 2002: 91).

En el discurso de Fuentes, el manejo de los estereotipos raciales emerge como una manifestación supuestamente documentada e ilustrada de las prácticas culturales. ${ }^{17}$ El suyo sería una suerte de racismo cientificista aparentemente basado en la observación de las conductas individuales y sociales. Naturalmente, no escapa a esa perspectiva un enfoque etnocéntrico y una nostalgia política e ideológica del Antiguo régimen que consagraba abiertamente un estatuto de desigualdad jurídica (Ramos Núñez 2002: 88).

\section{Una visión rápida. El "sujeto esclavista" en los textos político-jurídicos (1810-1880)}

Otro texto esencial es un importante libro del joven investigador Marcel Velázquez (2005), en el que resalta:

En el Perú existía una construcción jurídica de la esclavitud diseñada durante el Virreinato y heredera del derecho medieval de las Siete Partidas. Durante el siglo XIX y sus trastornos - desestructuración del orden virreinal, despliegue del proceso emancipador y consolida-

17 De esta manera, el Código Civil de 1852 fue expresión de la ideología de la época y recogía la división entre ingenuos, siervos y libertos. 
ción de las bases del Estado republicano- empieza a resquebrajarse dicha construcción y se genera la necesidad de una nueva representación discursiva y legal. En este contexto, los discursos de los juristas, en su afán de reconquistar una representación coherente, conducen al derecho a una situación límite que los enfrenta a nuevos presupuestos. El derecho esconde y revela, socava y legitima, pero lo que no puede hacer es prescindir de la esclavitud; al final, la contradicción será insostenible y la esclavitud desaparecerá y el derecho, transformado, ingresará al paradigma de la subjetividad plena y esto provocará la desaparición del sujeto esclavista en este ámbito (Velázquez 2005: 197).

\section{El autor plantea}

[...] como hipótesis de esta sección que los textos político-jurídicos sobre la esclavitud en el siglo XIX peruano demuestran el tránsito de la construcción jurídica de la alteridad al establecimiento de la semejanza propia de la subjetividad generalizada. Por ello, la mayoría de las posiciones discursivas se despliegan en dos vectores antagónicos: a) legalidad e ilegalidad de la institución, que era percibida fundamentalmente como una institución jurídica; y b) conflicto entre las ideas de propiedad e igualdad, es decir, la colisión entre el derecho de propiedad del amo y los derechos que se desprenden de la naturaleza humana del esclavo (Velázquez 2005: 197 y 198).

Otro dato curioso es que Unanue describe la variedad étnica en una forma exótica. ${ }^{18}$

18 “Unanue describe la diversidad étnica limeña de la siguiente manera: 'El color blanco salpicado de carmín en las mejillas; el pelo rubicundo; ojos azules; facciones hermosas; solidez en el pensamiento y un corazón lleno de fiereza generosa, son las características del europeo en su perfección y cultura. Un color cobrizo o amarillento, pelo negro y largo, ojos negros, facciones delicadas, aire melancólico, imaginación pronta y fuerte, corazón sensible y tímido: he aquí el retrato general del americano. Un pelo enraizado que no se levanta del casco, facciones salvajes, un color negro, espíritu pesado y un corazón bárbaro han tocado en triste herencia a la mayor parte de los africanos. La población de Lima se compone de esas tres naciones. Condujo a la primera la gloria de conquistar; la segunda es originaria del país, y la tercera ha sido arrastrada por las cadenas de la esclavitud. Estas diferentes tribus se han reunido, mezclado y hecho nacer entidades medias' (1974:110)" (Velázquez 2005). 


\subsection{Las plumas de los hacendados ${ }^{19}$}

José María de Pando (1787-1840), ${ }^{20}$ político capital en los primeros quince años de la República, “[...] es el testimonio viviente de la adaptación de los letrados a los cambios producidos por la Independencia y su capacidad de refrenarlos dentro de límites que preserven y garanticen su propia continuidad como clase dirigente" (Velázquez 2005: 203).

El texto de Pando obtuvo una victoria tardía. El 10 de marzo de 1835, el general Salaverry dictó un decreto estableciendo la legalidad del comercio e importación de esclavos de países americanos (Quirós 1831$42 ; \mathrm{V}, 50)$ en clara contradicción con la Carta Política de 1834²1. "Posteriormente, en el marco de la Constitución de 1839, la cual amparaba la posibilidad de importación de esclavos, se dictó la ley del 29 de noviembre de 1839, mediante la cual se ampliaba el tiempo de servicio de los libertos a sus amos hasta los 50 años (Quirós 1831-42;VI, 487)" (Velázquez 2005: 205).

Francisco de Rivero, en un agudo estudio sobre la economía agrícola del Perú, sostiene que la agricultura "Forma [...] el cimiento indestructible sobre el que las naciones edifican su riqueza; y es tan sólido ese cimiento, que aun en medio de cataclismos que echan por tierra los capitales resultantes del comercio y de las artes, la riqueza agrícola aunque se postergue ó paralice, jamás perece (1845:3)" (Velázquez 2005: 206).

José Gregorio Paz Soldán²2 “[...] envió el 19 de enero de 1846 una Memoria sobre la esclavatura en el Perú a la legislación británica representada por Guillermo Pitt Adams. [...]. Este texto combina una perspectiva

19 Usamos el término de Marcel Velásquez.

20 "Estudió en el Real Seminario de nobles de Madrid. Fue funcionario de Fernando VII entre 1815 y 1823. En 1824 retorna al Perú y fue Ministro de Hacienda y Ministro de Relaciones Exteriores del régimen bolivariano. Publicó la célebre Epístola a Próspero (1826) en honor de Bolívar, notable conjunción de la poética neoclásica y la defensa del autoritarismo. Posteriormente fue tres veces ministro del presidente Agustín Gamarra entre 1829 y 1833. Jorge Basadre lo califica como ‘la figura más importante entre los intelectuales autoritarios que acompañaron al primer gobierno de Gamarra' (HR, I: 280)”. Cita número 144 en Velázquez (2005: 203).

21 “El artículo 146 de la Constitución de 1834 establecía lo siguiente: ‘Nadie nace esclavo en el territorio de la república, ni entra ninguno de fuera que no quede libre' (Quirós 1831-42: v, 496)". Cita número 147 en Velázquez (2005: 205).

22 "Fue magistrado y político. Juez, fiscal y vocal de la Corte Superior de Arequipa, diputado por Arequipa en el Congreso Constituyente de Huancayo (1839) 
histórica y una argumentación jurídica que apunta a legitimar la importación de esclavos de Nueva Granada y Brasil y su empleo en la agricultura costeña" (Velázquez 2005: 206).

Se señala que "Las razones de la trata esclavista con destino a América son múltiples y de diversa naturaleza: religiosa (convertir a los antropófagos africanos al cristianismo), sociobiológica (sol y arenales requerían las constituciones fuertes de los sujetos africanos para afrontar el trabajo), económica (codicia mercantil), histórica (institución arraigada en la historia de Occidente)" (Velázquez 2005: 207).

Posteriormente, Paz Soldán

[...] revisa con detalle la legislación republicana sobre la esclavitud. Su perspectiva apunta a probar el siguiente silogismo: el desenfreno de las ideas liberales ha provocado la disminución drástica del capital humano de los agricultores; la legislación ha ido acrecentando los derechos de los esclavos mermando el derecho de propiedad de los amos; por ello, la agricultura se encuentra al borde del colapso por la falta de brazos y los elevados costos de mantener esclavos (Velázquez 2005: 207).

Toribio Pacheco, ${ }^{23}$ redactor principal de El Heraldo de Lima, considera que el decreto de abolición de Castilla fue un "error político, social, jurídico y económico. Políticamente, los afroperuanos no poseían conciencia de las posibilidades y responsabilidades de la libertad ni de sus derechos como ciudadanos; por ello, deberían haber sido sometidos a un patronato provisorio" (Velázquez 2005: 209). ${ }^{24}$

Pacheco, además, asevera frontalmente (Velázquez 2005: 210):

y senador por Arequipa (1845-49), tres veces ministro de Relaciones Exteriores(1845-48, 1853-54, 1862-63) y rector de la Universidad Nacional Mayor de San Marcos (1861-1863), la cual fue reorganizada y modernizada administrativa y académicamente bajo su gestión. Fue redactor de diversos periódicos doctrinarios, entre los que destacan La Bandera Bicolor (1839) y El Constitucional (185959) (Tauro 2001: XII, 1992-1993)". Cita número 149 en Velázquez (2005: 206).

23 “Ferviente defensor del régimen de Echenique porque coincidía con los ideales de modernización que el jurista preconizaba; por eso, calificaba el movimiento insurreccional de Castilla como mera asonada que trastornaba el orden constitucional (Ramos 1993:40)". Cita número 153 en Velázquez (2005: 209).

24 Sobre Toribio Pacheco, revísese el excelente trabajo de Carlos Ramos Núñez. 
En una editorial del periódico se planteaba que el ministro Ureta había ido más lejos que Moisés porque lanzaba a los esclavos a la vida social sin preocuparse porque los derechos y obligaciones emanados de la libertad se arraigaran en su práctica social y además los reconocía como [...] ciudadanos activos, como miembros de la sociedad política, sin embargo de que, hasta ese instante, no habían sido considerados ni como miembros de la sociedad civil, ¿qué decimos? Ni como miembros de la sociedad humana. (El Heraldo, 2 de junio de 1855, citado en Tardieu 2004: 370).

Santiago Távara, por otro lado,

[...] publica en 1855 el folleto titulado "Abolición de la esclavitud en el Perú". El autor, combinando el análisis legislativo, el análisis económico de las exportaciones de azúcar, el análisis histórico institucional comparativo y una incipiente sociología de los actos delictivos, demuestra cuatro proposiciones: a) los hacendados lograron revertir plenamente el sentido de las medidas legislativas pro-abolicionistas; b) la ruina de la agricultura no deriva de la falta de brazos, sino de las políticas económicas erradas que impiden ampliar la penetración en los mercados externos o de la sobreproducción por la modernización tecnológica; c) los propietarios de esclavos serán indemnizados con largueza por el gobierno; d) los esclavos recién liberados no se convierten en malhechores. Una característica que acompaña esta argumentación es la impregnación en el discurso de una visión providencialista y teleológica de cuño bíblico (Velázquez 2005: 211).

Manuel de Mendiburu (Velázquez 2005: 212), por otra parte, publica [...] en La Revista de Lima un artículo titulado "Ojeada sobre la esclavitud bajo el régimen colonial" (1862). [...]. El autor no deja de pronunciarse enérgicamente contra el mestizaje: "su mezcla y confusión sucesiva con la española, ha causado y causará males á la moral y al ilustre país" (1862:518). Desde una perspectiva racialista, hegemónica en los discursos culturales europeos de la segunda mitad del XIX, sostiene que la unión sexual entre blancos y negras durante todo el período colonial "produjo abatimiento á la raza blanca y mengua sin duda en las nobles dotes de su antiguo ser" (1862: 527). 
Finalmente, Ricardo Palma publica “Manumisión", 25

[...] informe oficial que fue la respuesta a una solicitud del gobierno de Brasil por conocer el proceso de abolición de la esclavitud en el Perú (Porras 1954:54). [...]. En el texto introduce la expresión corriente de "piezas de ébano" para designar a los esclavos, alude al feroz tratamiento que daban los amos a sus siervos y manifiesta su profundo rechazo al comercio infame de carne humana. Emplea el neologismo de "esclavócratas" para denominar a quienes requerían de la esclavitud para conservar su poder económico y social. Resaltando las maniobras y los argumentos de los hacendados, realiza una velada alusión al texto de Pando (1964:138-140) [Velázquez 2005: 213].

\section{La jurisprudencia}

a. El caso de José Faustino Sánchez Carrión ${ }^{26}$ y su bonhomía (Archivo Regional de La Libertad)

Compra del esclavo Sebastián Valdivieso para otorgarle libertad Identificación: División Notarial - Leg. 593. Escritura No. 37. Folios: 59 23 de abril de 1820 - Trujillo, Perú

José Sánchez Carrión - Ministro Universal de Estado de la República, de acuerdo a los principios de filantropía, libertad y patriotismo dio en libertad a su esclavo Sebastián Valdivieso a quien compró en la cantidad de trescientos pesos en la Ciudad de Lima a don Luis de Valdivieso, con la condición de que le acompañe en clase de un sirviente libre, mientras sea del gusto de Sebastián. Libertad graciosa y con solo la calidad expresada: se desiste, quita y aparta del derecho de posesión, propiedad y señorío, todo ello se lo dona, cede y renuncia y le da poder irrevocable para que trate, contrate, compre, venda, paresca [sic] en juicio, otorgue

25 “Se publicó en el libro Cachivaches (1900), el cual reúne textos de diversa naturaleza (históricos, literarios y bibliográficos)". Cita número 160 en Velázquez (2005: 212).

26 Es propiciador de la incorporación del indio y del negro dentro de la sociedad peruana y, en aras de la unión, abogó para que la familia peruana sea una sola, donde reine la justicia, la libertad, la seguridad y la prosperidad para todos los peruanos. Al lado de Simón Bolívar, supo luchar por la integración de América Latina, porque todos los pueblos tienen un objetivo común: la unión y la libertad. 
Escrituras, Testamentos y haga todo cuanto una persona libre y no sujeta puede hacer.

b. Un caso de sevicia contra dos negritos (Archivo Regional de La Libertad)

Sección: Judicial colonial

Cabildo - Causa ordinaria. Expediente N. 117- Legajo N. 65. Fecha 12 de febrero de 1807

El defensor de menores de la Ciudad de Menores de la Ciudad de Trujillo Don Manuel Vicente Merino en representación de Juana Rosa, sierva de Doña Josefa Naba, denuncia por sevicia a Cayetana Prieto, mujer legítima de Luis Arze por los crueles y aberrantes tratos a sus hijos Nasaria de nueve años y Juan de la Rosa de cuatro años. "Estos infelices y miserables siervos eran la víctima del furor de su indicada ama, con respecto a que siendo de notoriedad adolecen esta, de preocupaciones diabólicas a especie de locura, y que cuando se halla situada de este feroz mal, toma el tema ya con ponerles a estas débiles criaturas un cordón a la garganta con que intenta ahorcarlas, ya con meterlas las uñas entre las fauces con que las sufoca; ya con el doble castigo que excenta por cualesquiera nimiedad, que es consiguiente a edad tan corta, hasta el extremo de sajar sus tierras carnes [...]". ${ }^{27}$

c. Un caso de sevicia sobre una negra y su hija (Archivo Regional de La Libertad)

16 de abril de 1816 (438/4415/adll)

José del Carmen Fontao - negro criollo de la hacienda de Chiclin en el valle Chicama propio del señor Márquez de Herrera

Asunto: Se tase la persona e su hija y se proceda a su venta por los maltratos inferidos a su ama

Hija: Rosa, esclava de doña Manuela de Arangoitia

Contra: Manuela de Arangoitia

Se denuncia los maltratos dados a su esposa e hija, aún cuando éstas se encontraban en mal estado de salud y mutiladas respectivamente.

27 Texto paleográfico, tal como lo registró el funcionario del Archivo Regional de La Libertad. La trascripción la dejaremos aquí, pues el texto es muy extenso. Al final, los menores son entregados y vendidos a otro amo. 
También se solicita que el alcalde se limite a participar en el juicio por ser familiar cercano de sus amos.

Resolución del 7 de mayo de 1818, se notifica a Manuela de Arangoitia para que acuda al Juzgado, pues se negaba a hacerlo.

d. Se denuncia a negra por inquietar a los vecinos (Archivo Regional de La Libertad)

Pedimento:

18 de abril de 1818 (438/4416/adll)

Margarita Caballero - vecina de la ciudad de Trujillo y residente del asiento de La Asunción de Nuestra Señora de Chicama

Contra: Florencia - esclava negra criolla

Por: ser una advenediza e inquietar a los vecinos

Se solicita el destierro de Florencia por "ser una advenediza y llevar a todos los vecinos inquieto pues no hay día que no se levante unos torbellinos de disgustos y pleito por ella originando y se prejuicios por todas sus parte".

e. Caso Ciriaco de Urtecho (Archivo Regional de Cajamarca; director: Evelio Gaitán $)^{28}$

Autos seguidos por Ciriaco de Urtecho con Juan de Dios Cáceres sobre libertad de una esclava propiedad del segundo y mujer legítima del primero

24/12/1782

Petición:

Ciriaco de Urtecho - vecino del pueblo de Cajabamba, Huamachuco

Casado con: Dionisia Gracia

Contra: Jerónima de Gracia y Loris y Juan de Dios de Cáceres (marido de Jerónima, ama de la esclava)

Ciriaco de Urtecho solicita que don Juan de Dios de Cáceres o su esposa presente la escritura de venta de la esclava Dionisia para que se le abone el dinero del valor de dicha esclava y se le dé su libertad.

Escritura de venta:

28 Trazegnies (1995). 


\section{1/09/1754 Cajamarca}

Se vende a Dionisia (9 años de edad)

170 pesos

Escrito de Ciriaco:

“Cuando esta Esclava se compró tenía de edad nueve años, sobre que ahora se le agregan veinte y ocho y quedamos en que cuenta treinta y siete. Ella se halla habitualmente accidentada, tiene semblante de una Persona caduca y es constante que ha tenido cuatro partos de cuyos partos sólo han logrado subsanarnos [sic] el último [...].

Por estos poderosos fundamentos, tengo suplicados a dichos sus amos a fin de que reciban el importe de su Esclava que es el mismo en que fue comprada, pero se deniegan enteramente pretendiendo la perpetua Esclavitud de mi Mujer o la exorbitante cantidad de 500 pesos $[\ldots]^{\prime \prime}$.

“Tres Requisitos eran necesarios para esta simulada Usura: el primero, que no interviniera rescate; el segundo, la sanidad del esclavo y proporcionada edad para lograr producir frutos; $y$, el tercero, oficio conocido. [...].

El primer punto parece contiene una grande fuerza a favor de la Esclava por intervenir Rescate aún entre los Infieles, porque es innegable a todo Cautivo. El segundo es defecto grande por falta de salud, a causa de inhabilitarla para cualesquiera trabajo $[\ldots]$...

"La intención de don Juan de Dios Cáceres es incomprensiva porque se deniega por una parte a la recepción del Dinero, [...] por lo que patentemente se mira la poca gana que tiene de la libertad de ésta; y por otra, la infiere, él y doña Jerónima de Gracia su Mujer, gravísimas extorsiones, amenazas y violencias [...]. Éste es uno de los casos que previene el Derecho para que un Esclavo pruebe sevicia, por donde no es obligado a la servidumbre de aquel amo; cuánto más será en rescate".

Contestación de Juan de Dios de Cáceres:

“[...] la esclava se debe apreciar por peritos y Vuestra Señoría por su Auto, declarar el justo precio de ella; y entregándoseme éste, estoy llano a otorgar el Instrumento Carta de Libertad pretendida. Este es el estilo común y práctica recibida. [...]". 


\section{La jurisprudencia comentada por los especialistas}

Hemos señalado, al inicio, que el derecho por sí solo no puede explicar la institución de la esclavitud en el Perú, y esta disciplina tiene que apreciarse de manera conjunta o conectada con otras disciplinas, como la historia, la antropología y la sociología. Por este motivo, es necesario remitirse a investigadores de las ciencias sociales, como Jorge Basadre, Carlos Aguirre, Maribel Arrelucea, Humberto Rodríguez Pastor, Alberto Flores Galindo, Luis Millones, Roberto Mac-Lean y Estenós, Aldo Panfichi, Manuel Burga, entre muchos otros que iluminan el camino del estudio de la esclavitud en el Perú, la cual, como dice Aguirre en su Breve historia de la esclavitud en el Perú, es una herida que no deja de sangrar.

\subsection{Alberto Flores Galindo y su Aristocracia y plebe ${ }^{29}$}

El historiador, lamentablemente desaparecido en forma prematura, Alberto Flores Galindo señala: "Frente al esclavo negro, la clase dominante colonial sentía desconfianza y temor. Sentimientos subterráneos y preconscientes, de manera que pocos textos lo traslucen. [...] sino en la amenaza de una latente rebelión que destruyera las haciendas y saqueara las ciudades. [...] cómo los negros bozales de esa isla [Haití] consiguieron expulsar a los franceses y proclamar una república independiente. ¿Podría suceder lo mismo en el Perú?" Héctor Centurión Vallejo, brillante docente trujillano, nos explica que en una monografía presentada en la histórica Universidad Nacional de Trujillo, se trata del sitio de dicha ciudad por los negros. ${ }^{30}$

29 Flores Galindo (1984).

30 Centurión Vallejo (1953). En las páginas 39, 44, 45, 48, 53 y 54, el autor relata lo siguiente: “La campaña electoral de 1850 fue muy agitada e importante [...]. El Mariscal Castilla, Presidente de la República, apoyaba al candidato oficial General Rufino Echenique, quien tenía entre sus opositores al General Vivanco y al candidato civil D. Domingo Elías [...]. En ese ambiente de pugna y ajetreos electorales, se produjo en Trujillo una rebelión de negros esclavos del Valle de Chicama, del de Santa Catalina y de esta ciudad [Trujillo], con el objeto de obtener por las armas, el reconocimiento de su libertad". "Uno de los mentores ideológicos de la redención de los negros esclavos en Trujillo, fue [...] Dr. D. Fernando Casós [...] contó con un eminente profesor, el Dr. Alfonso Gonzáles Pinillos, quien enseñó a sus discípulos los derechos naturales, inalienables e invulnerables, como el derecho del hombre a nacer y permanecer libre [...] novela autobiográfica 'Los 
amigos de Elena'. Enseño, también, sus ideales sociales a Norberto Cedeño [...]. Convencido Cedeño, como su mentor intelectual, de la injusticia que sufrían sus hermanos de raza, se puso en contacto con algunos negros de las linajudas familias de la localidad, a los que aleccionó, asimismo, sobre los derechos que deberían conquistar los esclavos, por la fuerza de las armas". "Buen guitarrista y cantor, Cedeño [...] cantaba coplas contra la esclavitud. 'La pobreza Dios la amó/ mientras no supo lo que era,/más cuando la conoció/pegó tan fuerte carrera/que hasta el cielo no paró"”. "Cedeño después de mover a los negros de Trujillo y del Valle de Santa Catalina se trasladó con el mismo objeto al Valle de Chicama, en donde los negros eran más numerosos, a fin de tomar por las armas Trujillo y proclamar en la plaza principal su libertad. Con tal propósito consiguió de su 'Niño' Casós la redacción, de la correspondiente proclama, la misma que debería ser leída en el acto de conquistar la libertad. [...] levantamiento de los esclavos de Lambayeque, Chiclayo, Chancay y Pisco [...]. ‘Las leyes de la naturaleza y las del Estado protegen nuestra causa; nuestra personalidad es igual a la de todos, nuestros derechos también lo son: la esclavitud de unos es la afrenta de la libertad de los otros', los incita a la acción y al valor terminando la proclama con esta enardecida frase 'que se levanten hoy en todo el Valle de Chicama, proclamaremos hoy mismo la libertad de los esclavos en la plaza de Trujillo'". "En los últimos días de enero de 1851 [...] levantamiento de los negros de las haciendas Tulape, Bazán y Farías, con cuyo motivo le avisaba haberse trasladado al pueblo de Chicama en busca de auxilio para contener a los amotinados, sin conseguirlo por carecer de la autorización prefectural. [...] El 29 de Enero tuvieron los esclavos un choque sangriento en Ascope, siendo rechazados. [...] El día 30 se tuvo conocimiento en Trujillo de estas acciones por carta que la remitió de Chocope una comadre al General José María Lizarzaburu, avisándole además, que Valentín Baca [cabecilla apodado 'el Palmuyero'] había confesado que la rebelión obedeció a órdenes impartidas por dicho General”. “[...] Transcurría el día 31 y no llegaba ningún aviso de Díaz [teniente coronel], lo que produjo ansiedad y angustia en el vecindario, agravadas con las noticias; en cambio, que a cada momento llegaban de las operaciones de los sublevados, la inminencia de un asalto a la ciudad y la amenaza de muerte que flotaba en el ambiente. La noche del 31 de enero la población la pasó en vela. [...] la señora Mercedes Cavero de Ganoza, había sido amenazada de muerte por sus esclavos de su Hacienda Trapichito, del Valle de Santa Catalina, si regresaba a ella. [...] [Los negros] [a]vanzaron a Trujillo, por el camino de la Cumbre, llegando al pie de las murallas de la ciudad, por el lado de Miraflores, como a las 4 de la mañana, del día primero de Febrero. [...] Los esclavos pasaron la brecha, corrieron tras el Prefecto y tomaron posesión de la Plaza de Armar. Hubo cierre de puertas general. [...] Los revoltosos se apoderaron de todas las armas y municiones existentes en el cuartel de gendarmes, de donde volvieron en una bullanguera expresión de triunfo a la Plaza, procediendo a dar lectura a la proclama de su libertad y a exigir a grandes voces que los amos les extendie- 
sen la correspondiente escritura de manumisión. [...] envalentonados y triunfantes los negros esclavos por las ventajas obtenidas [les dieron 350 pesos del tesoro público], volvieron a pedir, insistentemente, se les extendiese la escritura pública de manumisión, a lo cual también accedió el Prefecto, mandando llamar al escribano Aguilar, a quién [sic] le proporcionó suficiente papel sellado ordenándole extendiera la carta de manumisión, que fue firmada por los amos, en cuya labora emplearon toda la noche y parte del día siguiente. [...] al siguiente día 2 de febrero amanecieron los negros sobre las armas, exigiendo con más insistencia se les otorgase la escritura de manumisión, que les fue entregada como a las 5 de la tarde. Con la carta en su poder se dirigieron con gran algarabía a la Plaza de Armas, y con repique general de campanas, publicaron con bando la libertad conquistada, a la que habían accedido todos los amos con el fin de evitar mayores desgracias a la población. La escritura de manumisión dice lo siguiente: '[...] esta carta de libertad amplia para todos los esclavos hombres y mujeres de nuestras respectivas haciendas, como también para todos los que viven y sirven en las casas de esta ciudad, sea quién fuese el amo a quién pertenezcan, pues para él y para su bien está apersonado en este documento el señor Síndico Procurador, entendiéndose que desde el acto de otorgada esta escritura que será firmada por este funcionario, serán libres al tenor de las leyes del año veintiuno y demás que constitucionalmente los favoresca [sic], especialmente en el decreto protectoral del generalísimo D. José de San Martín; todo lo cual hacemos y firmamos con la sola condición que han de trabajar en sus respectivas haciendas como personas libres a quiénes se les dará dos reales diarios, teniendo la libertad de separarse del fundo únicamente en el caso que no sean pagados en la antedicha cantidad diaria, pudiendo hacer su separación a donde les pareciera, previniendo aún más que los mencionados esclavos manumitidos no amenazarán a la tranquilidad pública ni a la vida de todos estos vecinos que se hallan en consternación'. 'Y que para esta carta pública surta todos los efectos legales, es otorgada ante el escribano y testigos que la firmarán en esta ciudad de Trujillo a primero de febrero del año del Señor de mil ochocientos cincuenta y uno. - Firmado - Pedro Joaquín Borgoño - Cecilio Gonzáles - Marcos del Corral - Josefa del Risco - Martín de Quevedo - José María de la Puente - Alejandro Pinillos - Valentín Castillo, Síndico Procurador - Manuel Bracamonte - Pedro Lisón Jaburú - Juan Luna Victoria - Josefa Zuáres - José Manuel Araujo - Serapio Orbegozo - Francisco Risco - Fernando Ganoza - Toribio Larraondo - Dolores Chopitea - Alfonso Gonzáles Pinillos - Manuela Guerrero [...] en Trujillo, fecha ut supra. - Signo. - fmado. José Vicente Aguilar, Escribano público de Hacienda del Estado y Rentas'. Con el júbilo que es de imaginar, los negros esclavos a las 6 de la tarde del día 2, después de publicar la carta de manumisión, abandonaron la ciudad con dirección a Mansiche, en donde pernoctaron entregados a festejar su libertad, sin que existiera ya en la ciudad, la amenaza de saqueo y latrocinios". "[...] General José María Lizarzaburu, con quien procedieron a armar al vecindario [...]. En la co- 
El autor de Buscando un Inca nos refiere el siguiente caso (no sin antes hacer un análisis exhaustivo del negro(a) en la sociedad colonial y la cantidad de casos distribuidos en el Perú, pero que por razones de espacio no podemos consignar):

La esclava Rosa Montenegro había nacido en Santiago de Chile, en la casa de don Juan Santa Cruz, quien la vendería a Josefa Santibáñez, vecina de Cailloma, de donde Rosa pasó a Arequipa. Allí -al parecer, por sus "vicios" y "malignidad" - cambió muchos amos, incluido el cura auxiliar del obispo de Arequipa. Se ignora cómo llegó a Lima, donde su primer amo acabó depositándola en una panadería. Estuvo fugitiva, hasta que la compró María Hurtado de Mendoza, quien, a su vez, la vendió por "prostitución" y acusada de tener varios "amancios". Una cierta picaresca rodeaba la vida de estos esclavos; fácilmente pueden deslizarse al mundo lumpen de la ciudad (Flores Galindo 1984: 121).

Otro caso muy interesante, también citado por Flores Galindo, se refiere al suicidio de un esclavo, que desde una perspectiva logra un doble beneficio: perjudica a su amo (a quien odia) y beneficia económicamente a su familia. El caso es de un

municación que el General Lizarzaburu dirigió al Tesorero le decía ‘La imperiosa necesidad de salvar al país de una horda de facinerosos que amagaba el reposo público y los intereses de sus vecinos, me han puesto en el caso de salvarlos, reuniendo la fuerza que creo necesaria para desalojar de él a los perturbadores del sosiego de sus habitantes y no existiendo en esta ciudad autoridad a quién dirigirme para pedir municiones, que me son indispensables, para completar la obra que he comenzado etc. [...]'. Termina esta comunicación solicitando los implementos anotados". "La carta de manumisión obtenida por los esclavos, quedó en consecuencia, sin efecto, como quedó sin efecto el juicio que a los cabecillas mandó abrir el nuevo Prefecto del Departamento Mariscal Antonio Gutiérrez de la Fuente, por la amnistía concedida por el Congreso. De los cabecillas, Alas, apodado 'El Código', y Honores, 'El Mereñeque', no se tuvo noticia. Cedeño, el sacristán, guitarrista y cantor, huyó a Lima, en donde trabajó primero como carpintero y después como doméstico personal de Casós, cuando éste fue a la Capital a seguir sus estudios de Derecho. El Mariscal Castilla, anoticiado del levantamiento de los negros al que se había querido dar tinte político, remitió una columna de tropa y equipo de artillería que se sumaron a las milicias que llegaron de San Pedro de Lloc". 
[...] negro llamado Antonio [...]. El gesto era producto de la desesperación, pero tenía un objetivo muy concreto que se descubre luego, cuando, como consecuencia del juicio, las autoridades prestan atención a esa familia de esclavos y condenan al amo a que otorgue una reparación a la viuda y los hijos en la cantidad de 150 pesos; consiguen así un alivio siquiera pasajero [...]. Para Antonio, probablemente, su tragedia personal y familiar era imputable a don Ignacio Meléndez, su amo, a quien había servido con "honradez", "juicio" y "conducta", sin ser debidamente recompensado. Al suicidarse consiguió un beneficio para su familia y un doble perjuicio económico a su amo: la pérdida del esclavo y el pago de la indemnización [...] (Flores Galindo 1984: 126).

\section{Los casos en Carlos Aguirre ${ }^{31}$ y Maribel Arrelucea ${ }^{32}$}

Hay que revisar los libros de estos dos estudiosos de la historia negra en el Perú, pues son sumamente exhaustivos en sus trabajos; no podremos citar la gran cantidad de casos, que van desde la simple sevicia hasta el cimarronaje, el bandolerismo, los palenques. Es tarea del investigador acucioso revisar sus trabajos, citados anteriormente, pues estos intelectuales han dedicado buena parte de su vida académica a tratar el tema de la esclavitud desde diversas miradas. Por ejemplo, Arrelucea tiene una perspectiva de género, sin dejar la rigurosidad en cuanto al análisis de castas y de etnicidad. Y Aguirre trabaja con mucha seriedad el papel de las panaderías como centro de torturas para los esclavos y el rol que juegan estos mismos para la búsqueda de su libertad a través del trabajo a desgano, los juicios ante los tribunales, la violencia e incluso el suicidio. Hay, pues, una deuda pendiente de nuestra parte para explorar, desde nuestra visión de abogados, el caso - verbigracia- de las panaderías, de las primeras prisiones, la evolución de la doctrina civil en materia de derecho de personas, etc.

31 Aguirre (2008). Este autor tiene muchos trabajos sobre el tema; uno recomendable es Aguirre (2005).

32 Arrelucea Barrantes (2009). También se puede revisar su excelente artículo: Arrelucea Barrantes (2007). 


\section{La continuidad histórica. Nos habíamos negreado tanto y una reflexión final}

Sacamos de su escondite el libro del psicoanalista Jorge Bruce, Nos habíamos choleado tanto, 33 y leímos buena parte de él por sus sesudas reflexiones. Desde la mirada del psicoanálisis del racismo en el Perú, no sólo se refiere al llamado cholo, sino que abarca al negro, al mestizo, al mulato, al zambo, al blanco, al chino, etc. El racismo es una verdadera afrenta a la civilización; no es solamente, como dice Martín Tanaka, un arcaísmo intolerable. No es arcaísmo, como si ya no existiera o fuera remanente el que queda. El racismo, lamentablemente, forma parte de nuestra sociedad; está arraigado en ella. Es como un parásito que bebe de nuestros prejuicios, de nuestra ignorancia, de nuestro inconsciente. Quizá, como dijo un autor, se trata de una continuidad histórica que tiene sus orígenes en las historias, en los hechos, que hemos reseñado. En lo que estamos de acuerdo es que es intolerable y una sociedad que se dice democrática debe ser incluyente; no de forma lírica, sino real y concreta. La historia y el derecho nos sirven como instrumentos para cambiar esta aberrante tara. Saquémosla de nuestras mentalidades e incorporemos la igualdad entre las personas de nuestro país. Habrá siempre muchísimo que hacer.

\section{Bibliografía}

Aguirre, Carlos (2008). Denle duro que no siente. Poder y transgresión en el Perú republicano. Lima: Asociación Fondo de Investigadores y Editores (Afined).

- (2005). Breve historia de la esclavitud en el Perú: una herida que no deja de sangrar. Lima: Fondo editorial del Congreso del Perú.

Arrelucea Barrantes, Maribel (2009). Replanteando la esclavitud. Estudios de etnicidad y género en Lima borbónica. Centro de Desarrollo Etnico (Cedet).

—_. (2007). “Lágrimas, negociación y resistencia femenina: esclavas litigantes en los tribunales. Lima 1760-1820". Summa Historiae. Año 2, núm. 2. Lima.

Bruce, Jorge (2007). Nos habíamos choleado tanto. Psicoanálisis y racismo. . $^{\mathrm{a}}$ impresión. Lima: Fondo Editorial de la Universidad de San Martín de Porres.

33 Bruce (2007). 
Centurión Vallejo, Héctor (1953). “Esclavitud y manumisión de negros en Trujillo". Revista Universitaria. Trujillo: Universidad Nacional de Trujillo

Flores Galindo, Alberto (1984). Aristocracia y plebe. Lima, 1760-1830. Lima: Mosca Azul.

Pareja Paz Soldán, José (2005). Historia de las Constituciones nacionales (1812,1879). Lima: Fondo Editorial de la Pontificia Universidad Católica del Perú.

Ramos Núñez, Carlos (2002). Historia del derecho civil peruano. Siglos XIX y XX. Tomo III: Los jurisconsultos: el Murciélago y Francisco García Calderón. Lima: Fondo Editorial de la Pontificia Universidad Católica del Perú.

— (2001). Historia del derecho civil peruano. Siglos XIX y XX. Tomo I: El orbe jurídico ilustrado y Manuel Lorenzo de Vidaurre. Lima: Fondo Editorial de la Pontificia Universidad Católica del Perú.

—. (2001b). Historia del derecho civil peruano. Siglos XIX y XX. Tomo II: La codificación del siglo XIX: los códigos de la Confederación y el Código Civil de 1852. Fondo Editorial de la Pontificia Universidad Católica del Perú.

Rodríguez Pastor, Humberto (2008). Negritud. Afroperuanos: resistencia y existencia. Lima: Centro de Desarrollo Étnico (Cedet).

Saponara, Manuel (2008). Inglaterra y la evolución de la esclavitud en el Perú: aspectos de política pública, 1820-1854. Lima: Fondo Editorial del Congreso del Perú.

Tardieu, Jean-Pierre (2004). El decreto de Huancayo, la abolición de la esclavitud en el Perú. Lima: Fondo Editorial del Congreso del Perú.

Trazegnies, Fernando de (1995). Ciriaco de Urtecho. Litigante por amor. Reflexiones sobre la polivalencia táctica del razonamiento jurídico. $3 .^{\mathrm{a}}$ edición. Lima: Fondo Editorial de la Pontificia Universidad Católica del Perú.

Velázquez Castro, Marcel (2005). Las máscaras de la representación: el sujeto esclavista y las rutas del racismo en el Perú (1775-1895). Lima: Fondo Editorial de la Universidad Nacional Mayor de San Marcos. 